\title{
Dreaming with a Wakeful Mind: The Gateway to Breaking the Illusion
}

\author{
Kanchi Vijay Srinath* \\ Moolji Jaitha College, India \\ Submission: June 28, 2017; Published: July 5, 2017 \\ *Corresponding author: Kanchi Vijay Srinath, Moolji Jaitha College, India, Tel: 09403673618;Email: vskanchi@gmail.com
}

\begin{abstract}
Illusion is the cornerstone on which the entire edifice of Advaita Vedānta of Hinduism and Mahāyāna of Buddhism are erected. Of the many classic examples adduced to illustrate the concept of illusion, appearance of silver in the nacre of a conch shell, snake in a rope and the dream experiences are most widely cited in the Indian philosophical literature. Illusion is a serious matter of concern to a philosopher as it reminds one that all knowledge experienced is not always valid and poses epistemological challenge as to how reality can be distinguished from illusion. The central reason for admission of illusion as reality is that we fail to recognize illusion as an erroneous mental representation at the time of experiencing it; we realize its falsity only afterwards. Our inability to realize illusion as a mere false cognition at the time of experiencing it is vital to our falling prey to it. We are carried away by the illusion because it does not occur to us that it could be unreal during its experience. In the wakeful state we would never know when we come across an illusion because for us, every experience seems real: it's only at a later time that we realize how we have mindlessly fallen prey to an illusion. But realizing an illusion afterward does not help in enlightenment. Enlightenment is when one wakes up during the occurrence of an illusory experience. Unfortunately, in the wakeful world we normally do not come to know beforehand that a particular piece of experience is illusory.

Dream is a unique illusory experience that we come across every day. Dream experiences are real as long as they last and every day we enter and exit the dream world without exception. Thus dream is a wonderful opportunity where we know beforehand that we are going to enter into an illusory world. Hence if we somehow learn to keep ourselves awake during the illusory experience of dreams, it would be a practicing ground for realizing illusion as it happens and find a way out. Hence dream state is an ideal ground for a practitioner to come out of illusion by practicing to stay put in lucid awareness and realizing the illusory nature during the course of a dream. Realizing the wakeful experiences as illusory is far harder than admitting the illusory nature of the dream state. Tibetan dream yoga is based precisely on this very principle. Milam or Tibetan Dream Yoga is one such practice that provides elaborate methodology for spiritual seekers to use dream state as an ideal platform for mastering spiritual enlightenment. It provides an elaborate procedure to recognize illusion, controlling it and finally get rid of it. This paper discusses the significance of dreaming with a wakeful mind to practice surmounting the clutches of illusion and tread on the path of enlightenment.
\end{abstract}

Keywords: Dream; Lucid dreaming; Illusion; Reality; Dream yoga; Milam; Tibetan buddhism; Advaita

\section{Introduction}

Every day, we the human beings, on an average spend one third of our life span (about eight hours) in sleep and dreaming. Out of these eight hours, we spend about ninety to one hundred and twenty minutes in dream reveries. This is the time where we create a world within ourselves, a virtual world within the world that sometimes is more fantastic and realistic than the real world. Yet, while most us have no contention in accepting the reality of the external world arising out of sensory experiences, give credence and value it, we simply underrate and write off the dream world as sheer figment of our imagination that is inevitably experienced daily. But the fact remains that while one is dreaming, the experiences are utterly real and the dreamer experiences pleasure and pain, awe and fear, hatred and anger, in the same way as is experienced during wakeful hours. The dreamer does not know that the objects of the dream world are only mental creations and fails to distinguish between objective physical world experienced empirically and conceptual mental world. The dream objects exhibit all the qualities and characteristics of physical objects and offer sensory experiences that correspond to the wakeful experiences of the physical world.

As we withdraw from the external world, every day without exception, we enter into a strange, illusory and deceptive world. 
Here is an illusion that we know we would inevitably fall victim to, taking the dream objects and resulting experiences as utterly real, yet we don't make any effort to keep ourselves mindful to save ourselves from that everyday predicament. In a sense we take pleasure in being fooled every day in and day out accepting unreal as real. This raises several philosophically significant questions both in epistemology and in ontology which perturbed the philosophers across the timeline: If we are being fooled everyday by a non-entity as being really existing and even an iota of doubt does not arise in us while experiencing it, what is the guarantee that the present moment of experience we have now is also not illusory? What qualifies something as real and something else as illusory? If illusions were to be discarded gradually, where would one finally end?

Philosophers across the timeline have been fascinated with this line of thought -many were perplexed by the sheer semblance between dream and waking world experiences and despaired to find a way to distinguish the two. But the meditative yogis of ancient India and Tibet not only found a solution to 'wake up' to higher consciousness during dream time but also devised an elaborate mechanism, a point to point roadmap for maneuvering the dreamscape and even controlling, which, according to them would ultimately qualify them to steer through this grand illusion called samsāra. Called Svapna darşana in Sanskrit and Milam in Tibetan yogic parlance, this secretive doctrine has been relegated to mere yogic lore all these years. However advancements in dream studies coupled with recognition of lucid dreaming as a practicable genuine phenomenon of consciousness in the recent times, have now unfurled the innumerable possibilities 'controlled dreaming' can offer to a philosopher in search of ultimate truth. Dream world is an ideal ground to experiment with different dimensions of illusion and practicing to recognize illusion and coming out of it, provided one is able to realize the dream as such while he is experiencing the dream. But is it possible to 'wake up' to the realization that what is experienced is a dream, without disturbing the very dream and allowing it to continue? If this is somehow mastered and if the same technique is employed in the wakeful experiences, does such practice lead one to a higher state of consciousness?

\section{The Problem of dream in east and western thought}

The problem of nature of dream world has always fascinated the spiritualists and philosophers of east and west throughout the ages. The fact that we don't realize that we are dreaming while we are in the dream state led many philosophers to wonder whether one could actually be dreaming constantly, instead of being in waking reality. Or in other words, it may just be impossible to certainly state at any given point in time that one is not dreaming.

The Greek philosopher Plato considered this problem in Theaetetus. In the dialogue between Theaetetus and Socrates, Socrates asks Theaetetus whether he could supply any veridical proof to anybody, should anybody ask them, whether they were asleep at that moment and their thoughts were a dream or whether they were really talking to each other in a waking condition. Theaetetus contemplates and replies in agreement'Really, Socrates, I don't see what proof can be given; for there is an exact correspondence in all particulars, as between the strophe and antistrophe of a choral song. Take, for instance, the conversation we have just had: there is nothing to prevent us from imagining in our sleep also that we are carrying on this conversation with each other, and when in a dream we imagine that we are relating dreams, the likeness between the one talk and the other is remarkable'. The dialogue turns further interesting when Socrates exclaims-'So you see it is not hard to dispute the point, since it is even open to dispute whether we are awake or in a dream' and further contends that -'in each state our spirit contends that the semblances that appear to it at any time are certainly true, so that for half the time we say that this is true, and for half the time the other, and we maintain each with equal confidence' [1].

In his magnum opus Metaphysics, Aristotle also describes the difficulty or rather impossibility of distinguishing between appearance and reality by stating "wondering whether we are at any given moment asleep or awake" [2]. Rene Descartes, employing the method of doubt also wondered if it was really possible to ascertain and distinguish the reality of the external world from that of the dream world in his Meditations on First Philosophy. Descartes noted that the testimony of the senses with respect to any particular judgment about the external world may turn out to be mistaken. He contends that the most vivid dreams that he occasionally experiences are internally indistinguishable from waking experience and so it is possible that everything that he perceives to be part of the physical world outside him at the moment, could be in fact nothing more than a fanciful fabrication of his own imagination. (Med. I)

In 1923, a prominent Physician and editor of a Journal titled Practical Medicine, Ram Narayana [3], brought forth an interesting problem in front of the intellectual community by eliciting solutions to the dream problem. A dreamer who often dreams similar dreams, once stops his dream mates and tells them that they are his mental creation and that he comes to this world from another world by the name wakeful world and if he returns to his world or if he wishes, he could came his dream mates vanish into thin air and that their existence is entirely dependent upon him. The persons in the dream, though at first out rightly reject and laugh at the utterances of the dreamer, finally give him a patient hearing and agree to believe his version, if only he could manage an object from his wakeful world into the dream world as a proof of existence of some other world than their world of dream. Ram Narayana stops at this and asks the intelligentsia to come up with suitable solutions as to how an object, as a proof can be transported into the dream world from the wakeful world. This problem was circulated to well known philosophers, doctors, scientists and engineers of that time and a compendium of suggested solution was published under the title 
"The Dream Problem and Its Many Solutions" in two Volumes. This caught the imagination of the academicians, philosophers and scientists of that time and is still debated occasionally in the psychology and philosophy circles.

Zhuangzi a Chinese emperor, who ruled around 369 BC, raised an interesting enigma that demands serious consideration. He says he dreamt he was a butterfly and wonders whether he indeed was the emperor Zhuangzi who had just finished dreaming he was a butterfly or whether he was a butterfly who had just started dreaming that he was emperor Zhuangzi (1996)! We might just dismiss this as mere play of words or figment of imagination and say the existence of Zhuangzi as an emperor is real and his experience of being a butterfly is illusory because we know that he was an emperor of China. But while doing so, we are conceding his existence as the emperor beforehand and so our standpoint is biased and thus, is a case of logical fallacy. We might further argue that his emperor's existence' is more real because it outlived the experience as the butterfly. But again this is a contention from the point of view of the waking world. During his existence as the butterfly at no point of the time Zhuangzi felt it was ephemeral. Looking from the dreamscape, the dream world appears complete in itself and feels as though it would last forever. Further, it would be fallacious to quantify the dream time with the scale of waking world because they are two different worlds each having their own timescales. Unless a device or mechanism is devised that can measure the two worlds with the same standard, comparing the dream world and the waking world from the waking world's point of view will be fallacious. This popular parable is what Zhuangzi calls as the great dream paradox.

\section{Mandukya karika}

The Mandukya Upanishad of Atharva Veda with its twelve verses describes $\mathrm{Om}$ with its three mātras of a, $\mathrm{u}$ and ma, as the all encompassing Supreme Reality and equates these three mātras with wakeful, dream and deep sleep states. It speaks of a fourth state of consciousness called turiya which runs as the undercurrent through these three states and which also transcends these three states allowing one to experience these states as experiences of one Subject.

Gaudapadacharya in his Māndukya kārika elaborated on the Māndukya Upanishad and described in detail the experiences of these three states and proves how impossible it is to ascribe reality to one state and unreality to the other. It brings to fore certain oft overlooked issues such as the fact that we live our lives in three disconnected states of wakefulness, dreaming and sleeping. We are not able to remember the previous state of ours once we move into another state and that particular state we enter into will become really real for us. Yet there is a connecting thread lying as undercurrent in all these states which can be realized through our prospective memory. Prospective memory is one which we employ to remind ourselves about a thing or event at a future point of time. Waking up at a specific time to attend to an important meeting is one such example. This same prospective memory can be trained and drastically improved to connect us more strongly with the three states will full awareness as we wade through them. The Māyāvāda of Şankara also equates the empirical world with that of fantasy and illusion. Māndukya kārika's attempt is to present dream as an inevitable illusion that we are sure to experience everyday and show it as an opportunity to relook and reassess our understanding of reality [4].

\section{Why philosophical study of dream state is important}

Of the least understood subjects, even in today's knowledge based scientific world, is the nature of dream world. Why do we dream and why do we fail to recognize during our dream that what all experienced is just our own mental creation still eludes satisfactory explanation. Though the advent of psychoanalysis as a system of treatment in the early twentieth century by Sigmund Freud generated considerable interest in the dream analysis and interpretation of the meaning of dreams [5], philosophy of dreams concerning the ontological and epistemological issues were never seriously considered by the philosophers. Even Freud complained of the apathy and nonchalance of philosopher toward dream study, he complained that philosophy regards this whole topic as intellectually unworthy and second-rate. Though there are many intricate philosophical questions that crop up owing to our daily experience of dream state it never received the serious consideration that every philosopher must owe to it. For example, how and why do we experience objects and events in dreams even though there is no physical existence of such objects eludes satisfactory epistemological explanation. Similarly how to define reality becomes more complicated when one takes into account the utterly convincing dream experiences. Further other philosophical questions like whether we are answerable to our dreams and whether we engage in karma during dreaming etc., open up the Pandora box. Some of the greatest scientific discoveries and inventions, some of the finest creative ideas are attributed to the dream reveries. For example the molecular structure of Benzene was conceived by Augustus Kekule as he dreamt of a long serpent biting its tail and this gave him the idea of cyclic structure of Benzene. At least four Nobel prizes are attributed to the dream time creative illumination. There are several reports of precognitive dreams throughout the history in which the dreamer has a premonition about occurrence of a future event.

\section{How dream world is different from the wakeful world}

A significant part of the human life is spent in dream and deep sleep yet the portion of human life spent in these states is not under the conscious control of the human beings. While in the waking state humans have at least a limited degree of control on the sensory experiences and are endowed with the powers of discretion, logical judgment, introspection, etc., the dream state and deep sleep states divest them of these abilities. On the other hand surprisingly the dream world sometimes offers 
extraordinary abilities which he would otherwise not possess in the wakeful state. The dream world does not seem to follow the laws of physics and one can fly in dreams. Further the dream time seems independent of the waking life time. In dreams we could fly back into our past, a facility not supported by the wakeful world. With our rather numbed logical faculties, our dream world seems to obey a set of unfamiliar logical rules that are alien to our waking world. However the most challenging aspect of dream state is the fact that while we are dreaming [6] we hardly ever realize that the experiences are illusory and unreal.

\section{Lucid dreaming}

Post 1950s, there has been renewed interest to study the nature of sleep and dream, thanks to the discovery of Random Eye Movement (REM) and non-REM sleep cycles by William C. Dement and Nathaniel Kleitman in 1953. Even by that time there have been many people who claimed that they knew they were dreaming while they were dreaming and some even claimed that they could alter the course of their dreams as per their liking. However such claims could not be validated and there was no way to check whether somebody could still be not awake and yet realize that he is dreaming. In 1970 Keith Hearne, for the first time successfully managed to record pre-determined eye movement signals communicated by a lucid dreamer to the external world (researcher). The lucid dreamer, his brain scans confirmed without doubt, was still sleeping and was having dreams yet was not only aware that he was dreaming but could also convey it to the outside world through definite signals. This was the first ever recorded communication between dream world and waking world. This stands tangentially opposite to what Ram Narayana wanted as a solution in his dream problem in 1923-to carry an object or signal from the waking world into the dream world. This ability of lucid dreaming is not limited to some extraordinary people alone but this skill is learnable and cultivatable. The world of lucid dreaming opens up new pathways toward our philosophical understanding concerning knowledge and reality.

Charlie Morley defines Lucid dreaming as a dream in which we are actively aware that we are dreaming as the dream is happening. Morley puts them as "as among the most thrilling experiences to be had". It is 'a full-colour, high-definition and hyper-realistic experience that can profoundly reconfigure our perceptions of reality' [7]. This is a mind training in which instead of being passive recipients of dream experiences we take conscious control of ourselves in dreams which in turn confers on us the ability to control the dream events. Whether it be dream or wakeful life, we are usually carried away unawares by the currents of our thoughts and tendencies and seem to enjoy very limited conscious control on the events. Charlie Morley [7] contends that till such time one experiences dreams in full lucidity, one will be tempted to think dreams only as unreal and inconsequential. "When we become lucid in our dreams and learn to stabilize that lucidity, we quickly learn that a lucid dream is as real as waking reality. It's just a reality with different dimensions". This inevitably wakes us up to the important fundamental question of ontology: "what is reality?". Lucid dreaming is not easy to master, but it is undeniably one of the most exciting and rewarding practices we may ever engage in, with a wealth of both psychological and spiritual benefits. It cultivates mindfulness in dream and sleep and enables an insight into the nature of reality that is incomparable. It is a completely safe practice, open to all ages and abilities, offering a unique insight into our own psychology. In a letter to a mourning friend Albert Einstein once wrote, 'A human being... experiences himself, his thoughts and feelings as something separated from the rest-a kind of optical delusion of his consciousness... To try to overcome this delusion is the way to attain true peace of mind.' By practicing to dream lucidly we can learn to overcome this delusion.

In any dream, whether or not it is lucid, the reality is that both the subject and objects of experience are produced from the subjective self only. Though a dream character might stand up and display wrath and the dreamer may experience fear at the very same time, in fact the dreamer, the dream characters and their contrasting emotions are produced from the same subjective self! The same unitary consciousness projects itself as many. However in an ordinary dream we fail to recognized this very vital point. In a lucid dream we have an opportunity to realize this reality fully, as it is happening. Thus lucid dreaming compels us to face directly the notion of māya which argues that all the experience of duality is but a delusion and that the only ultimate reality is but the consciousness.

\section{Milam-dream yoga}

Interestingly, thousands of years ago, the meditative yogis of India and Tibet found a way out to break the eternal wheel of illusion by realizing that subduing completely one illusion in all its dimensions will train the consciousness to subdue all other kinds illusions, and that dream is a nature's gift to master the technique of breaking the illusion. The Tibetan Buddhist School started by revered master Padmasambhava in 8th century CE, known by the name Dzogchen or Atiyoga, is a system that considers the perceived reality as mere appearance and as unreal. In this tradition Dzogchen there is a mystic practice called Milam, which is popularly known in the western world as Dream Yoga which describes various practices that are exclusively meant to understand, predict and control the dreams. Described as part of the advanced spiritual practices known by the name "the six yogas of Naropa" this Milam practice is known in Sanskrit as Svapnadarśana and intended to enable the practitioner to realize the identicalness of dream world and the world experienced in wakefulness which would finally lead the practitioner to realize the emptiness of these two worlds.

As Chögyal Namkhai Norbu, a prominent Tibetan Buddhist teacher puts it: "In a real sense, all the visions that we see in 
our lifetime are like a big dream ...". Waking world, just like the dream, is also an experience. And we cannot be certain of the 'reality' of the external world absolutely; all that we in fact know is our experience. For an uninitiated, the mentally created conceptual world is no different from the sensory world. He feels the dream world is also a result of employing his senses and fails to find any sign or symbol that points to him that he is dreaming. This inability to recognize is an illusion with no escape route. By training the mind, cultivating and fine tuning the faculties of recognition, mindfulness, and alertness one could recognize the illusion as it is happening. This becomes the way to breaking the illusion experienced in the form of dream. When this practice is steadily developed this acute sense of mindfulness and alertness, enables the practitioner someday, to wake up from the illusion of the external world.

The similar nature of dream experiences and the so called after death experiences is emphasized in the Bardo Thodal or the Tibetan Book of the Dead. If one is carried away by the illusory experiences encountered in the dream world daily, he has no escape from similar experiences the consciousness experiences at and after the time of death. If one has not practiced to stay alert in dreams, one is bound to be tormented by the after life experiences, because after all both are the experiences of the consciousness at different altered states. "If we cannot carry our meditative practice into sleep", Tenzin Wangyal Rinpoche [8] writes, "If we lose ourselves every night, what chance do we have to be aware when death comes? Look to your experience in dreams to know how you will fare in death. Look to your experience of sleep to discover whether or not you are truly awake".

\section{Conclusion}

Friedrich August Kekule who discovered the structure of Benzene ring said 'Let us learn to dream, and then we may perhaps find the truth' [9]. Every day, human beings enter into the dream world as passive participants, subjected to the vagaries of the dream world unwittingly, having no control on the events. While the scientists and philosophers make serious attempt to improve the quality of the external world and thereby improve the wakeful world, their attention is hardly drawn to

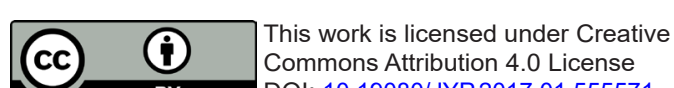

DOI: 10.19080/JYP.2017.01.555571 the dream world experiences despite the fact that this state takes appreciable amount of one's life time and its experiences are valid and real as long as they last. Thanks to advances in lucid dreaming, it is now an attested fact that a dreamer can train himself to experience his dreams mindfully and experience the dream world with full consciousness and even control the experiences. This learnable technique of lucid dreaming, which was well documented in the ancient yogic literature as Milam or Svapnadarşana, not only raises many epistemological and ontological issues but also provides complete answers to the question of knowledge and existence. The technique of lucid dreaming developed in the west in the recent past and the age old Tibetan Dream Yoga offer some great solutions to stay conscious and wakeful throughout our dream experience. Now-a-days, aficionados of lucid dreaming have even identified chemical supplements, dietary regimen and devised methodologies that guarantee a person to experience dreams lucidly, challenge illusion directly and realize answers to the eternally pestering questions of illusion and reality all by himself. By practicing these techniques one could not only enrich his whole life but also utilize the practices for one's spiritual enlightenment.

\section{Reference}

1. Plato, Theaetetus, Translated by Benjamin Jowett, The internet Classic Archives, Online edition.

2. G Bell and Sons, Aristotle (1896) Metaphysics, English Translation John Henry MacMahon.

3. Ram Narayana (1923) The Dream Problem and Its Many Solutions, Practical Medicine.

4. Nikhilananda Swami (1949) The Mandukya Upanishad with Gaudapada Karika and Sankara's Commentary, Sri Ramakrishna Asrama: Mysore, India.

5. Descartes Rene, Jonathan Bennett (2007) Meditations on First Philosophy, www.blackmask.com, online edition.

6. https://en.wikipedia.org/wiki/Dream_argument.

7. Morley Charlie (2013) Dreams of Awakening, Hay House: London.

8. Rinpoche Tenzin Wangyal (2010) The Tibetan Yogas of Dreams and Sleep, Motilal Banarsidas: New Delhi, India.

9. Freud S (1951) The Interpretation of Dreams, Allen \& Unwin, London.

\section{Your next submission with Juniper Publishers} will reach you the below assets

- Quality Editorial service

- Swift Peer Review

- Reprints availability

- E-prints Service

- Manuscript Podcast for convenient understanding

- Global attainment for your research

- Manuscript accessibility in different formats

( Pdf, E-pub, Full Text, Audio)

- Unceasing customer service

Track the below URL for one-step submission https://juniperpublishers.com/online-submission.php 